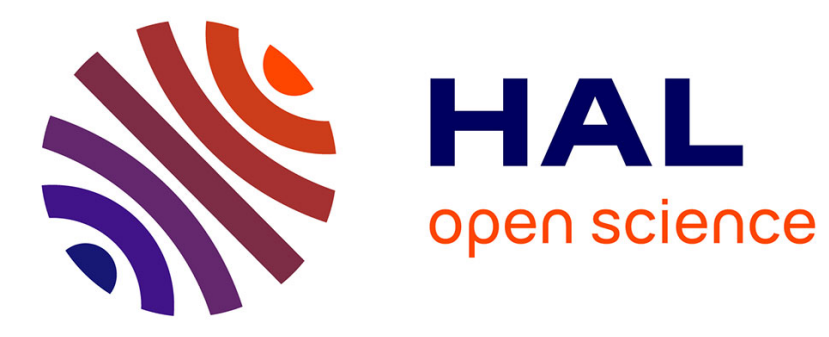

\title{
Quenched microemulsions: a new route to proton conductors
}

Cecile Noirjean, Fabienne Testard, Jacques Jestin, Olivier Tache, Christophe

Dejugnat, David Carriere

\section{- To cite this version:}

Cecile Noirjean, Fabienne Testard, Jacques Jestin, Olivier Tache, Christophe Dejugnat, et al.. Quenched microemulsions: a new route to proton conductors. Soft Matter, 2014, 10 (32), pp.59285935. 10.1039/c4sm00849a . hal-01157193

\section{HAL Id: hal-01157193 \\ https://hal.science/hal-01157193}

Submitted on 13 Nov 2015

HAL is a multi-disciplinary open access archive for the deposit and dissemination of scientific research documents, whether they are published or not. The documents may come from teaching and research institutions in France or abroad, or from public or private research centers.
L'archive ouverte pluridisciplinaire HAL, est destinée au dépôt et à la diffusion de documents scientifiques de niveau recherche, publiés ou non, émanant des établissements d'enseignement et de recherche français ou étrangers, des laboratoires publics ou privés. 


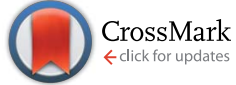

Cite this: Soft Matter, 2014, 10, 5928

\title{
Quenched microemulsions: a new route to proton conductors
}

\author{
Cecile Noirjean, ${ }^{a}$ Fabienne Testard, ${ }^{a}$ Jacques Jestin, ${ }^{\text {b }}$ Olivier Taché, ${ }^{a}$ \\ Christophe Dejugnat ${ }^{\complement}$ and David Carriere*a
}

\begin{abstract}
Solid-state proton conductors operating under mild temperature conditions $\left(T<150{ }^{\circ} \mathrm{C}\right)$ would promote the use of electrochemical devices as fuel cells. Alternatives to the water-sensitive membranes made of perfluorinated sulfonated polymers require the use of protogenic moieties bearing phosphates/ phosphonates or imidazole groups. Here, we formulate microemulsions using water, a cationic surfactant (cetyltrimethyl ammonium bromide, CTAB) and a fatty acid (myristic acid, MA). The fatty acid acts both as an oil phase above its melting point $\left(52{ }^{\circ} \mathrm{C}\right)$ and as a protogenic moiety. We demonstrate that the mixed MA-CTA film presents significant proton conductivity. Furthermore, bicontinuous microemulsions are found in the water-CTAB-MA phase diagram above $52{ }^{\circ} \mathrm{C}$, where molten MA plays both the role of the oil phase and the co-surfactant. This indicates that the hydrogen-bond rich MACTA film can be formulated in the molten phase. The microemulsion converts into a lamellar phase upon solidification at room temperature. Our results demonstrate the potential of such self-assembled materials for the design of bulk proton conductors, but also highlight the necessity to control the evolution of the nanostructure upon solidification of the oil phase.
\end{abstract}

Received 18th April 2014

Accepted 4th June 2014

DOI: $10.1039 / c 4 s m 00849 a$

www.rsc.org/softmatter independently of water content, using protogenic groups like phosphonates and imidazoles. ${ }^{2}$

Other potential protogenic groups consist of fatty-acid molecules. When spread at the air-water interface, they exhibit significant bidimensional proton conductivity through hydrogen bonds between carboxylate headgroups and presumably involving the first few layers of water molecules. ${ }^{3-5} \mathrm{We}$ highlight that (i) the reported $2 \mathrm{D}$ proton conductivity at the surface of fatty acid monolayers is of the order of $\sigma_{2 \mathrm{D}}=10^{-7} \mathrm{~S}$; in a hypothetical material made of well-aligned, compact and defectless bilayers of fatty acids, renormalisation by the typical molecular sizes $\left(l \approx 25 \AA\right.$ for myristic $\left.\operatorname{acid}^{6}\right)$ indicates an upper bound for the bulk (3D) proton conductivity of the order of $\sigma_{3 \mathrm{D}}=\sigma_{2 \mathrm{D}} / l=2 \mathrm{~S} \mathrm{~cm}^{-1}$ (ii) $2 \mathrm{D}$ conductivity is observed provided the area per molecule is below a critical value, of the order of 35-40 $\AA^{2}$. These conclusions indicate the potential of fatty acids as starting materials for proton conductors, if their assembly is sufficiently controlled at the molecular level in order to ensure a molecular area below the threshold value, and well-aligned bilayers parallel to the conducting path.

Here, we take advantage of the specific properties of a catanionic surfactant made of the association between a linear fatty acid (myristic acid, MA) and a cationic surfactant (cetyltrimethyl ammonium bromide, CTAB) to investigate the possibility to assemble them into bulk materials with proton conducting properties. First, we demonstrate that the mixed bilayers formed by these so-called "catanionic" mixtures ${ }^{7,8}$ show significant proton conduction as bulk solid-state materials. However, 
the proton conductivity value in the as-prepared micron-sized catanionic aggregates remains low compared to the hypothetical upper value of the order of $1 \mathrm{~S} \mathrm{~cm}^{-1}$. This motivates assembling the proton conducting catanionic films into bicontinuous films; we further demonstrate that above the melting point of myristic acid, the mixed film stabilises a bicontinuous microemulsion, i.e. forms a mixed MA-CTA film with a percolating hydrogen bond network. We find that quenching at room temperature fails to preserve the nanostructure of the liquid-state microemulsion. Our results therefore demonstrate the possibility to design bulk proton conductors from fatty acids, but also highlight the necessity to better control the nanostructure of the microemulsions upon solidification of the oil phase.

\section{Materials and methods}

\section{Sample preparation and phase diagram}

All chemicals were used as received. For the dialysed MA-CTA mixtures, the required amounts of $\mathrm{CTAB}, \mathrm{MA}$ and water are stirred at $50{ }^{\circ} \mathrm{C}$ for two days (MA-CTA $=1 / 1 \mathrm{~mol},(\mathrm{MA}+\mathrm{CTA}) / \mathrm{H}_{2} \mathrm{O}=1 \%$ weight). The turbid solution is then transferred into dialysis bags (regenerated cellulose, $10 \mathrm{kDa}$ cutoff) and dialyzed against a 5-fold volume of MilliQ water during five days. The dialysis bath is changed every hour on the first day, then three times a day. The dialysis step ensures removal of the $\mathrm{HBr}$ released upon association of MA and CTAB. ${ }^{9}$ Dialysis also progressively enriches the MA-CTA mixture in the less soluble MA, leading to the final composition plateau at a MA-CTA ratio of $64 / 36$, as previously described. The final composition of the dialysed MA-CTA mixtures is therefore $\left(\mathrm{C}_{13} \mathrm{COOH}\right)_{0.77}\left(\mathrm{C}_{13} \mathrm{COO}^{-}\right)\left(\mathrm{CTA}^{+}\right)$, where $\mathrm{C}_{13}$ stands for the $\mathrm{C}_{13} \mathrm{H}_{27}$ alkyl chain of myristic acid.

For the microemulsions, the required amounts of cetyltrimethylammonium bromide (CTAB, Acros), myristic acid (MA, Fluka) and MilliQ water, $\mathrm{D}_{2} \mathrm{O}$ (Eurisotop), or $10 \mu \mathrm{M}$ Rhodamine $6 \mathrm{G}$ aqueous solution (Invitrogen) are homogenised by stirring at $80{ }^{\circ} \mathrm{C}$, and left unstirred at controlled temperature (thermostatic bath, $20-80{ }^{\circ} \mathrm{C} \pm 0.1{ }^{\circ} \mathrm{C}$ ) for at least one week. The microemulsions have not been treated by dialysis, and their nominal composition is directly controlled by the amount of MA, CTAB and water. The phase diagram has been established by visual inspection of the mixture. The microemulsions have been cooled down in ambient air, liquid nitrogen and liquid ethane without noticeable difference in the X-ray scattering results.

\section{Dielectric spectroscopy}

Impedance spectra were recorded using a Hewlett Packard impedancemeter HP4192A with an oscillating potential of 20 $\mathrm{mV}$ in the frequency range of $5 \mathrm{~Hz}$ to $500 \mathrm{kHz}$. The sample was placed in a homemade conductivity cell with two platinum electrodes and a cell constant of $1 \mathrm{~cm}^{-1}$. In order to extract the conductivity (or resistivity) of the sample, the complex impedance $Z$ has been renormalised to the geometry of the sample: $z=S / t Z$ with $S$ the surface area and $t$ the thickness (typically, 1 $\mathrm{cm}^{2}$ and $1 \mathrm{~mm}$ respectively).

\section{SANS}

Small-angle neutron scattering (SANS) measurements were performed at the Laboratoire Léon Brillouin (LLB, CEA de Saclay) on the SANS two dimensional detector spectrometer PAXE. Three configurations were used: a sample-to-detector distance $D$ of $1.255 \mathrm{~m}$ with $\lambda=4 \AA$, $\lambda=7.8 \AA$, and $\lambda=12 \AA$. Samples were measured in $1 \mathrm{~mm}$ thick Hellma quartz cells thermalized by external circulation coupled to in situ temperature measurement $\left(T=15-90{ }^{\circ} \mathrm{C} \pm 0.1^{\circ} \mathrm{C}\right)$. Data processing was performed using PAsiNET software. ${ }^{10}$ To get the differential cross-section per volume in absolute units $\left(\mathrm{cm}^{-1}\right)$, the incoherent scattering cross-section of $\mathrm{H}_{2} \mathrm{O}$ was used as a calibration standard. It was obtained from measurement of the attenuator strength, and of the direct beam with the same attenuator.

\section{SAXS/WAXS}

Small and wide X-ray scattering (SAXS/WAXS) have been performed on a home-made apparatus in the wavevector range $2 \times$ $10^{-2} \AA^{-1}<q<3 \AA^{-1}$. The X-ray source (rotating molybdenum anode, $\lambda=0.709 \AA^{-1}$ ) is collimated via an Osmic mirror through two hybrid slits $\left(1 \times 1 \mathrm{~mm}^{2}\right)$. The beam scattered through the sample (glass capillary, $3 \mathrm{~mm}$ diameter, thermalized via a home-made temperature controller) was collected on a Mar 345 image plate, with a sample-detector distance of $72 \mathrm{~cm}$ (calibrated with tetradecanol). The detector count is normalized to differential cross-section per volume with $3 \mathrm{~mm}$ water and 3 $\mathrm{mm}$ Lupolen as a secondary reference $\left(I_{\max }=6 \mathrm{~cm}^{-1}\right)$, with a photodiode mounted on the beam-stop to monitor the photon flux. ${ }^{11}$ The incoming flux is found to be $9 \times 10^{7}$ photons per second.

\section{Differential scanning calorimetry (DSC)}

The thermal behavior was determined by DSC using a Mettler Toledo DSC 1 STARe System Thermal Analysis calorimeter equipped with a Gas Controller GC200. Samples were sealed inside aluminium crucibles of $40 \mu \mathrm{L}$ in volume. In order to ensure sample homogeneity, two heating/cooling cycles were performed as prescans between $25^{\circ} \mathrm{C}$ and $85^{\circ} \mathrm{C}$ at a rate of $10^{\circ} \mathrm{C}$ $\min ^{-1}$. Then thermograms were recorded by applying a heating/ cooling cycle between $25{ }^{\circ} \mathrm{C}$ and $85{ }^{\circ} \mathrm{C}$ at a rate of $1{ }^{\circ} \mathrm{C} \mathrm{min}{ }^{-1}$.

\section{Infrared spectroscopy (IR)}

IR spectra were recorded at the Chemistry Institute of Toulouse (ICT - FR CNRS 2599) using a Nexus Nicolet iN10 MX FT-IR microscope from ThermoScientific, equipped with a heating/ cooling system ensuring temperature control (within $0.1^{\circ} \mathrm{C}$ ) of the samples. The temperature was varied between $25^{\circ} \mathrm{C}$ and $80{ }^{\circ} \mathrm{C}$, and spectra were acquired every $5{ }^{\circ} \mathrm{C}$.

\section{Optical and confocal microscopy}

Optical observations have been performed on samples prepared with a $10 \mu \mathrm{M}$ Rhodamine 6G (Invitrogen) solution in water as the aqueous phase using an inverse microscope (Olympus, IX 81). Fluorescence emission of Rhodamine $6 \mathrm{G}\left(\lambda_{\mathrm{exc}}=543 \mathrm{~nm}\right)$ 
was integrated in the 555-655 $\mathrm{nm}$ range with a FV 1000 spectral confocal head (Olympus).

\section{Results}

\section{Proton conductivity}

Dielectric spectroscopy (Fig. 1) has been performed on a myristic acid-cetyltrimethylammonium (MA-CTA) $=64 / 36$ mixture after dialysis to eliminate the $\mathrm{H}^{+} \mathrm{Br}^{-}$ions released upon association of the surfactants. ${ }^{9}$ In the Cole-Cole $\left(z^{\prime}, z^{\prime \prime}\right)$ representation where $z=z^{\prime}+\mathrm{i} z^{\prime \prime}$ is the complex impedance normalised by the geometry of the sample, the spectra present a semicircle followed by a straight line at low frequencies, which are assigned to ionic conduction and electrode polarisation, respectively. ${ }^{12}$ The intercept of the semicircle with the $z^{\prime}$ axis gives a resistivity that corresponds to an ionic conductivity value of $2.710^{-7} \mathrm{~S} \mathrm{~cm}^{-1}$. This ionic conductivity is assigned to the migration of the protons at the surface of the mixed MA-CTA bilayers. Such lateral proton conductivity has already been reported in Langmuir monolayers of lipids, including fatty acids (e.g. stearic and palmitic acids). ${ }^{5,13}$ The proton conductivity of fatty acids becomes significant at low surface area per headgroup (typically, 35-40 $\AA^{2}$ ), and is mediated by proton transfer through the hydrogen bond network formed by the carboxylate headgroups and the first layers of water molecules. Consistently, it has been demonstrated previously that in the MA-CTA mixtures, the mean area per surfactant is $20 \AA^{2},{ }^{14}$ below the critical values for the emergence of proton conductivity. Furthermore, these bilayers consist of a mixture of protonated myristic acid (-COOH headgroups), deprotonated myristate molecules $\left(-\mathrm{COO}^{-}\right)$, whose charge is compensated by CTA molecules $\left(-\mathrm{N}\left(\mathrm{CH}_{3}\right)^{+}\right.$headgroups $) .{ }^{15}$ As a result, the bilayers present a mixture of proton donors and acceptors, respectively the headgroups of myristic and myristate molecules, which potentially allows proton migration by hopping even at low concentrations of water molecules. ${ }^{1}$

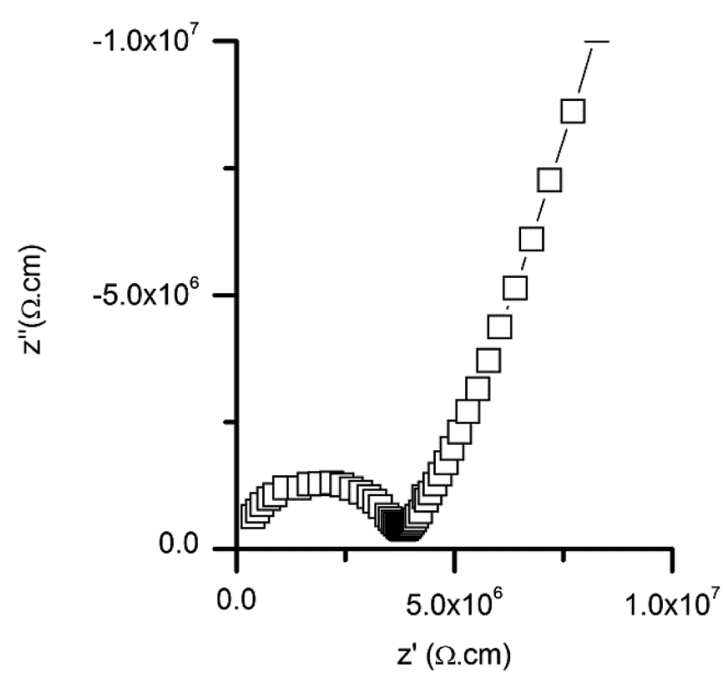

Fig. 1 Dielectric spectroscopy of micron-scale aggregates of CTAMA bilayers of composition $\left(\mathrm{C}_{13} \mathrm{COOH}\right)_{0.77}\left(\mathrm{C}_{13} \mathrm{COO}^{-}\right)\left(\mathrm{CTA}^{+}\right)$.
Impedance spectroscopy therefore supports the possibility to prepare materials with proton conducting properties from MACTA mixtures. However, the performances are modest compared to the upper limit of $2 \mathrm{~S} \mathrm{~cm}^{-1}$ as estimated from the conducting properties of single fatty acid films. This outlines the necessity to shape the films at the molecular scale in order to build a percolating bidimensional network while maintaining a low area per chain. For this purpose, we have explored the possibility to formulate microemulsions where the mixed MACTA film stabilises the interface between water and molten myristic acid.

\section{Phase diagram}

Myristic acid (MA) melts at $52{ }^{\circ} \mathrm{C}$ and forms an oil phase with little solubility with water $\left(\approx 10^{-5} \mathrm{~mol} \mathrm{~kg}{ }^{-1}\right.$ at $\left.60{ }^{\circ} \mathrm{C}\right) .{ }^{16}$ Accordingly, in the absence of surfactant (cetyltrimethylammonium bromide, CTAB), macroscopic phase separation is observed between water and liquid MA at $60{ }^{\circ} \mathrm{C}$. Addition of CTAB strongly enhances the macroscopic MA-water solubility. In particular, the macroscopic phase separation vanishes at a MA-CTAB-water $=70 / 19 / 11$ weight composition. The phase diagram at a fixed MA-water $=0.16$ ratio and variable $T$ and CTAB surfactant content $\gamma$ (Fig. 2) shows also the usual features of the so-called "fish-cut" of a microemulsion-forming system: ${ }^{17}$ a three-phase body is intercepted in the "head" of the fish, while the microemulsion domains are observed in the "tail" of the fish.

\section{Nanostructure of the microemulsions}

The nanostructure of the clear, isotropic mixture has been investigated by SANS. The mixtures prepared with $\mathrm{D}_{2} \mathrm{O}$ instead of $\mathrm{H}_{2} \mathrm{O}$ show a correlation peak around $q_{\max }=0.16 \AA^{-1}$ assigned to the nanostructure of the oil/water partitioning (Fig. 3). The lineshape is in good agreement with the Teubner-Strey equation with additional constant incoherent scattering: ${ }^{18}$

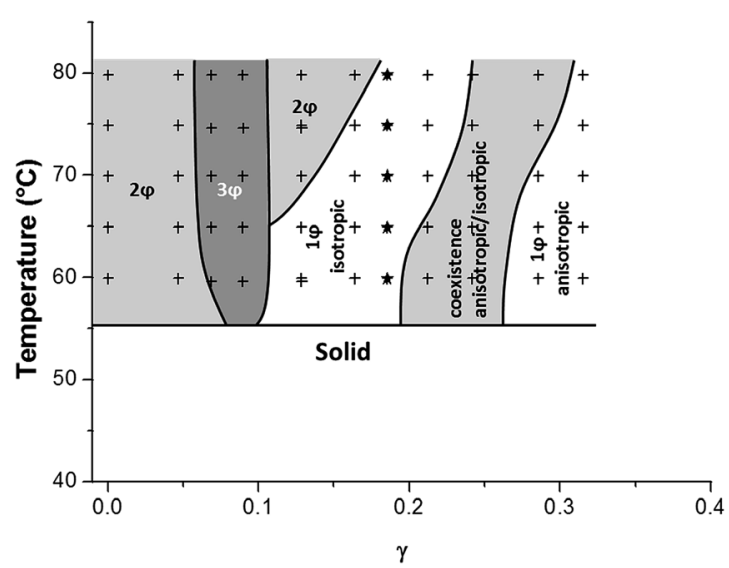

Fig. 2 Cut of the MA-CTAB-water phase diagram at constant water$M A=0.16$ (weight) and variable CTAB weight fraction $(\gamma)$. Crosses and stars are experimental points. Stars are samples studied in the rest of the article. Lines are guide to the eye. 


$$
I(q)=\frac{8 \pi}{\xi} \frac{\phi(1-\phi)(\Delta \rho)^{2}}{\lambda^{4}-2 \mu^{2} q^{2}+q^{4}}+I_{\mathrm{inc}}
$$

where $I$ is the normalized differential scattering cross-section per solid angle per unit volume, $I_{\text {inc }}$ is the incoherent scattering, $\phi$ is the volume fraction of either the polar or the non-polar phase, $\Delta \rho$ is the contrast in scattering length density. The correlation length $\xi$ and period $d$ of the pair correlation function are given by:

$$
\begin{gathered}
\frac{1}{\xi^{2}}=\frac{1}{2}\left(\lambda^{2}-\mu^{2}\right) \\
\left(\frac{2 \pi}{d}\right)^{2}=\frac{1}{2}\left(\lambda^{2}+\mu^{2}\right)
\end{gathered}
$$

This shows that the period of the correlation extends typically over $d=40 \AA$ with a range $\xi=36 \AA$ (Table 1). No dependence with temperature in the $66-80{ }^{\circ} \mathrm{C}$ range has been observed (Fig. 3), nor significant differences between SAXS and SANS patterns (Fig. 4a). The characteristic length of the microemulsion is remarkably short $(d=40 \AA)$, as it corresponds typically to twice the length of a CTAB or MA molecule, or to the thickness of a mixed CTA-MA bilayer in water $(d=52 \AA) .{ }^{15}$ The correlation length is close to the periodicity, which reflects loosely ordered structures. Furthermore, the volume fraction of the non-polar phase (oil phase + surfactant chains) is found extremely high (98\%) despite the zero mean curvature. It therefore suggests a nanostructure similar to a disordered network of oil-rich collapsed sponge phases, also referred to as "diluted bicontinuous" phases, ${ }^{19}$ or high internal phase microemulsion (HIPME) ${ }^{20}$ Very few examples of such a microstructure have been experimentally evidenced for microemulsions. Recently, the topology of these "frustrated microemulsions" has been predicted as a function of the rigidity and the composition of the

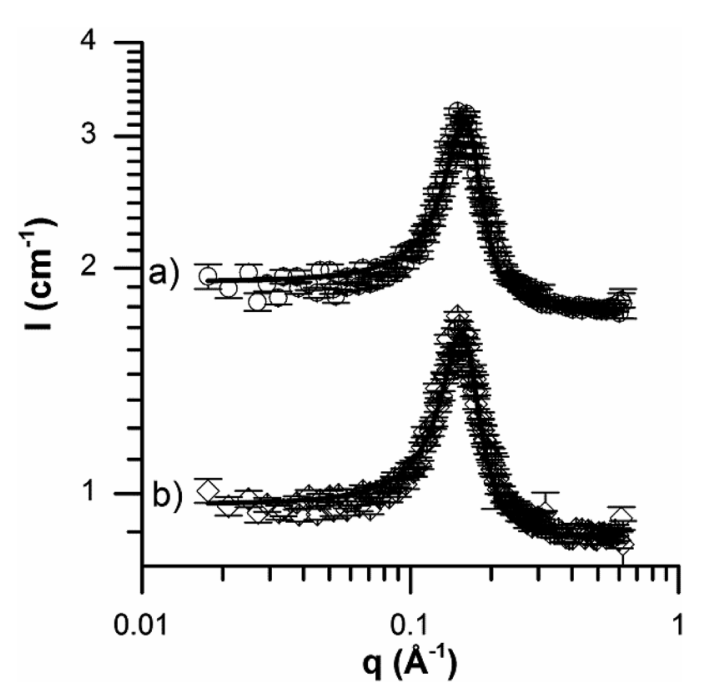

Fig. 3 SANS pattern of a MA-CTAB- $\mathrm{D}_{2} \mathrm{O}=70 / 18 / 12$ weight $\%$ mixture. (a) $T=76{ }^{\circ} \mathrm{C}$ (multiplied by 2 for clarity) and (b) $T=66^{\circ} \mathrm{C}$. Lines: best fits with the Teubner-Strey equation.
Table 1 Adjusted parameters to fit the Teubner-Strey equation with the SANS data of the isotropic microemulsions (MA-CTAB- $\mathrm{D}_{2} \mathrm{O}=70$ / $18 / 12 \%$ weight) according to eqn (1), with $\Delta \rho=6.3 \times 10^{-6} \AA^{-2}$ : the correlation length $(\xi)$ and period $(d)$ of the pair correlation function, the volume fraction of the apolar phase $(\phi)$ and the incoherent scattering $\left(I_{\text {inc }}\right)$. Error bars on each parameter indicate a $10 \%$ deviation on the $\mathrm{chi}^{2}$ upon optimization of all other parameters

\begin{tabular}{lllll}
\hline$T$ & $d(\AA)$ & $\xi(\AA)$ & $\phi(\% \mathrm{v} / \mathrm{v})$ & $I_{\text {inc }}$ \\
\hline $66^{\circ} \mathrm{C}$ & $40 \pm 1$ & $36 \pm 3$ & $97.9 \pm 0.5$ & $0.88 \pm 0.03$ \\
$76{ }^{\circ} \mathrm{C}$ & $39 \pm 1$ & $36 \pm 4$ & $97.9 \pm 0.5$ & $0.88 \pm 0.03$ \\
\hline
\end{tabular}
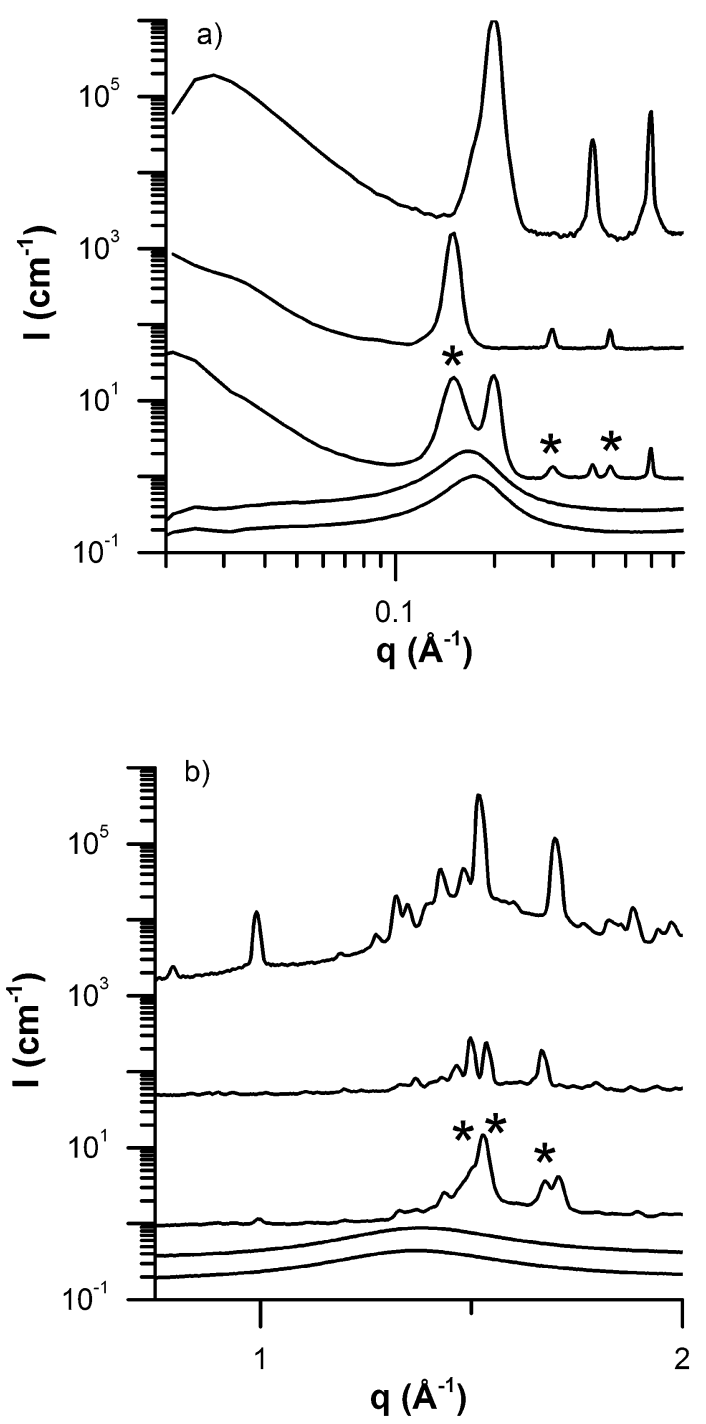

Fig. 4 X-ray scattering patterns of MA-CTAB-water mixtures, (a) in the SAXS and (b) in the WAXS regime, respectively. From top to bottom: myristic acid at room temperature (multiplied by $2 \times 10^{5}$ ), $\mathrm{MA}-\mathrm{CTAB}$ equimolar mixture at room temperature (multiplied by 200 ), ternary $M A-C T A B-\mathrm{H}_{2} \mathrm{O}=70 / 19 / 11$ weight\% mixture at room temperature (multiplied by 10 ), the same at $60^{\circ} \mathrm{C}$ (multiplied by 2 ), the same at $80^{\circ} \mathrm{C}$. Stars indicate the Bragg peaks assigned to the mixed MA-CTA-water lamellar phase. 
solution $^{19,21}$ showing a locally lamellar structure for rigid frustrated microemulsions.

\section{Thermal behavior and structural response}

Differential scanning calorimetry (DSC) shows that the microemulsions experience two reversible first-order phase transitions at $T_{\text {onset }}=52{ }^{\circ} \mathrm{C}$ and $T_{\text {onset }}=70{ }^{\circ} \mathrm{C}$ (Fig. 5). The first transition temperature coincides with that observed for myristic acid (Fig. 5a), whereas the second transition temperature coincides with that of equimolar MA-CTA mixtures prepared without water (Fig. 5c). The first endothermic peak is therefore assigned to the melting of the oil phase (MA), whereas the second endothermic peak is assigned to thermal transition of a mixed MA-CTA amphiphilic film at the oil/water interface (a socalled catanionic film ${ }^{\mathbf{8} 15}$ ).

This qualitative assignment is supported by quantitative exploitation of the thermograms. Comparison of the melting enthalpies of myristic acid and of the microemulsion shows that $91 \% \pm 1 \%$ of the myristic acid melts during this first transition, i.e. the rest of the myristic acid forms an amphiphilic complex with the CTAB molecules in the MA-CTA $=0.5$ ratio.

Remarkably, the lower-temperature transition $\left(52^{\circ} \mathrm{C}\right)$ occurs with a strong, reversible change in the nanostructure (Fig. 4a and b) whereas the second transition $\left(70^{\circ} \mathrm{C}\right)$ occurs without any detectable structural change (Table 1, Fig. 3 and 4). The lowertemperature transition is assigned to the solidification/melting of the oil phase (myristic acid). At room temperature, the sample is white and solid, and SAXS/WAXS (Fig. 4) demonstrates the coexistence of two phases: first, myristic acid crystals which produce most of the Bragg peaks in the 0.1-3.5 $\AA^{-1}$ range (Fig. 4a and b, top). Furthermore, in the ternary MA-CTABwater mixture at room temperature, the SAXS/WAXS pattern of myristic acid crystals is superimposed with four Bragg peaks of regular spacing $\left(\Delta q=0.15 \AA^{-1}\right)$, and a series of Bragg peaks at

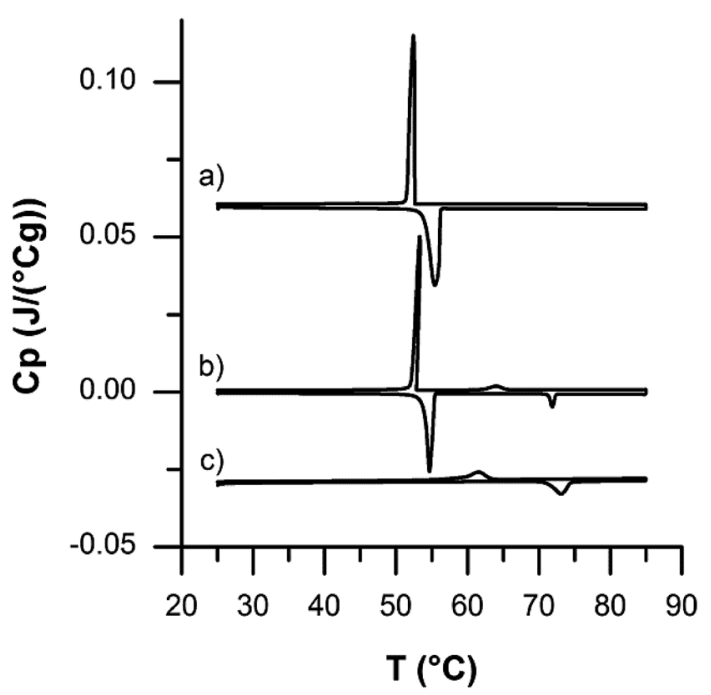

Fig. 5 DSC scans $\left(1^{\circ} \mathrm{C} \mathrm{min}^{-1}\right.$ ) of (a) myristic acid (offset of $0.06 \mathrm{~J}^{\circ} \mathrm{C}^{-1}$ $\mathrm{g}^{-1}$ ), (b) a $\mathrm{MA}-\mathrm{CTAB}-\mathrm{H}_{2} \mathrm{O}=70 / 19 / 11$ weight\% mixture and (c) an equimolar MA-CTAB mixture (offset of $-0.03 \mathrm{~J}^{\circ} \mathrm{C}^{-1} \mathrm{~g}^{-1}$ ). $q=1.49 \AA^{-1}, 1.54 \AA^{-1}$ and $1.67 \AA^{-1}$ (Fig. 4a and b, stars). This additional signature is assigned to a mixed MA-CTA-water lamellar phase with a repeating distance of $2 \pi / \Delta q=42 \AA$. The presence of Bragg peaks both in the SAXS and the WAXS regime supports that the mixed lamellar phase shows long-range order both in directions perpendicular and longitudinal to the lamellae. Consistent with this assignment, the Bragg peaks of the mixed lamellar phase are observed in equimolar mixtures of MA and CTAB (Fig. 4). At lower angles $\left(q<0.1 \AA^{-1}\right)$, the intensity decays as $q^{-3}$ due to the interface between MA and the mixed lamellar phase. The absence of the $q^{-4}$ signature of a smooth interface (the so-called Porod's law) is a proof of the roughness of the interface at these characteristic scales $(>10 \mathrm{~nm})$. This demonstrates that phase separation between the lamellar phases occurs, similar to the emulsification failure in the classical all-liquid microemulsions stabilized e.g. by $n$-alkyl poly(ethoxy) surfactants. ${ }^{17,22}$

In an opposite manner, the second phase transition is assigned to the melting of the mixed amphiphilic film, but occurs without detectable structural changes (i.e. no curvature change): neither the microemulsion periodicity nor its correlation length as determined are affected (Fig. $3 \mathrm{a}$ and b, and Table 1) despite the well-defined endothermic peak (Fig. 5). This lack of response originates from the nature of the high-temperature transition occurring in the film at $70{ }^{\circ} \mathrm{C}$, which we have elucidated using IR spectroscopy as a function of temperature.

\section{Elucidation of the higher temperature transition}

At low temperature $\left(T<52{ }^{\circ} \mathrm{C}\right)$, the mixtures therefore consist of a solid mixture of myristic acid and the MA-CTA- $\mathrm{H}_{2} \mathrm{O}$ lamellar phase. These lamellar structures vanish simultaneously and form the microemulsion at a melting temperature that coincides with that of myristic acid $\left(T_{\mathrm{m}}=52{ }^{\circ} \mathrm{C}\right)$. This suggests that myristic acid alone melts at the first transition and that the mixed lamellar phase organizes at the water/liquid MA interface. The second thermodynamic transition $\left(T_{\mathrm{m}}=70^{\circ} \mathrm{C}\right)$ is not accompanied by any detectable change in the nanostructure. This suggests that it corresponds to a transition of the MA-CTA interfacial film.

This interpretation is supported by infrared spectroscopy results as a function of temperature (Fig. 6). In the 1600-1800 $\mathrm{cm}^{-1}$ range, characteristic of the carbonyl $\mathrm{C}=\mathrm{O}$ vibrations (stretching), three series of spectra are observed. They are respectively characteristic of the mixtures below and above both thermal transitions. Below $52{ }^{\circ} \mathrm{C}$, the spectra are dominated by the vibrations at $1689 \mathrm{~cm}^{-1}$ and $1701 \mathrm{~cm}^{-1}$, assigned to MA cyclic dimers in the solid phase, ${ }^{23}$ and a band at $1724 \mathrm{~cm}^{-1}$. The latter wavenumber value is an intermediate between that of the strongly bound cyclic MA dimers, and that of the free monomers $^{24}\left(1774 \mathrm{~cm}^{-1}\right.$ and $\left.1785 \mathrm{~cm}^{-1}\right)$. The band at $1724 \mathrm{~cm}^{-1}$ is therefore assigned to the $\mathrm{C}=\mathrm{O}$ vibrations in the mixed CTA-MA lamellar phase.

Above the low-temperature phase transition $\left(52{ }^{\circ} \mathrm{C}\right)$, the vibrations assigned to the myristic acid cyclic dimers (1689 $\mathrm{cm}^{-1}$ and $1701 \mathrm{~cm}^{-1}$ ) strongly decrease (Fig. 6b, squares), whereas the vibration assigned to the MA-CTA complex 
a)

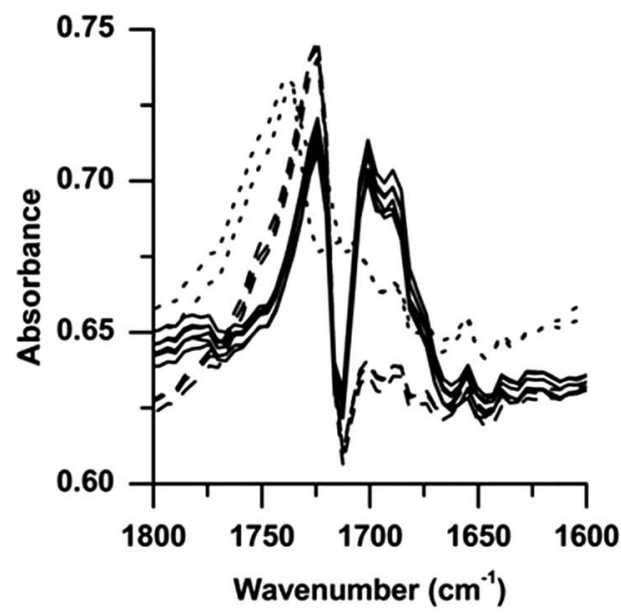

b)

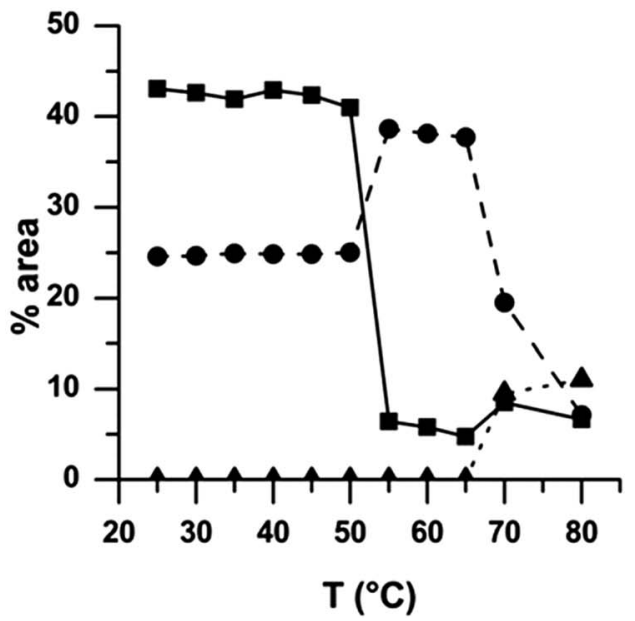

Fig. 6 Infrared spectra of a MA-CTAB- $\mathrm{H}_{2} \mathrm{O}=70 / 19 / 11$ weight\% mixture as a function of temperature. (a) IR spectra in the carbonyl $\mathrm{C}=\mathrm{O}$ stretching vibration region at different temperatures (full lines: in the $25-55^{\circ} \mathrm{C}$ range; dashed lines: in the $55-65^{\circ} \mathrm{C}$ range; dotted lines: in the $70-80{ }^{\circ} \mathrm{C}$ range). (b) Relative area of the peaks as a function of temperature (squares: myristic acid dimers, 1701 and $1689 \mathrm{~cm}^{-1}$; circles: $1724 \mathrm{~cm}^{-1}$; triangles: $1709 \mathrm{~cm}^{-1}$ )

increases (1724 $\mathrm{cm}^{-1}$, Fig. 6b, circles). This is consistent with the melting of the solid MA, and with an increased fraction of MA in interaction with CTAB by uptake of MA into the mixed interfacial film. Above the second phase transition $\left(70{ }^{\circ} \mathrm{C}\right)$, the intensity of the band at $1724 \mathrm{~cm}^{-1}$ decreases strongly, whereas vibrations at $1709 \mathrm{~cm}^{-1}$ (Fig. 6b, triangles) and at higher wavenumbers appear (1736 $\mathrm{cm}^{-1}$ and above). The second phase transition is therefore assigned to the weakening of the interactions with the carbonyl moieties in the mixed CTA-MA interfacial film.

We therefore assign the second phase transition to the rupture of the hydrogen bond network formed at the surface of the amphiphilic MA-CTAB film at the interface between water and oil (molten MA). This assignment is further supported by the enthalpy associated with this transition (13 kJ per mole of chain in the MA-CTAB complex), which is consistent with values usually reported for hydrogen bond networks in fatty acids. ${ }^{25}$ Furthermore, the formation or destruction of such a hydrogen bond network is expected to alter only marginally the bending modulus of a mixed equimolar MA-CTA bilayer. ${ }^{26}$ Assuming similar behaviour for monolayers, we elucidate the absence of nanostructure modification as the higher-temperature transition is crossed (Fig. 3 and 4).
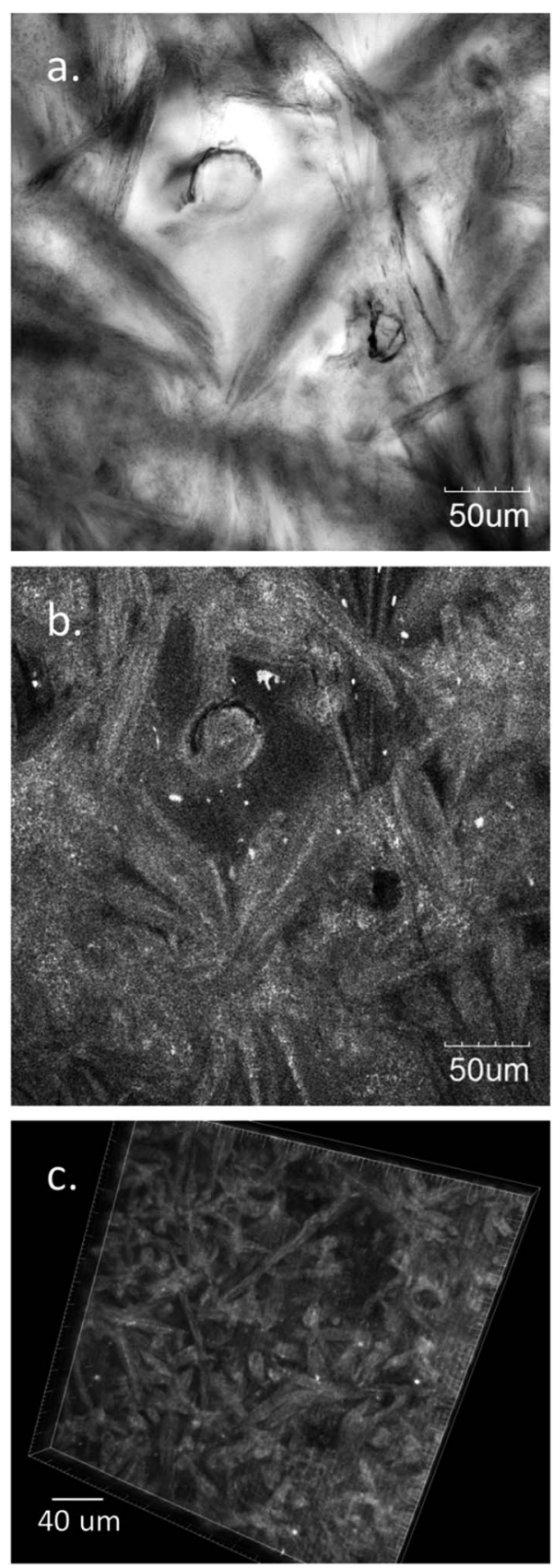

Fig. 7 Microscopic observations of a solid sample $\left(T<52{ }^{\circ} \mathrm{C}, \mathrm{MA}-\right.$ CTAB-10 $\mu$ M Rhodamine 6G aqueous solution = 70/19/11 weight\% mixture). (a) The two types of crystals seen in optical microscopy. (b) Segregation of the mixed MA-CTA lamellar phase (bright regions) from pure myristic acid (dark regions) as observed by confocal microscopy and (c) needle-shape of mixed MA-CTA lamellar phases embedded in myristic acid after 3D-reconstruction from confocal images. 


\section{Crystallisation}

Below the low-temperature phase transition $\left(T_{\text {onset }}=52{ }^{\circ} \mathrm{C}\right)$, the microemulsion converts reversibly into the mixture of myristic acid crystals and of the mixed lamellar phase (Fig. 4). The mixed lamellar phase is unable to self-assemble at temperatures above the crystallisation temperature of myristic acid, as shown by SAXS and SANS in the $60-70{ }^{\circ} \mathrm{C}$ range (Fig. 3 and 4). The formation of the mixed lamellar phase is therefore not driven by the formation of hydrogen bonds, but rather by the crystallisation of myristic acid. Upon crystallisation of the solvent (myristic acid), the segregation of the aqueous nanodomains is forced, as observed upon freezing of colloidal suspensions. ${ }^{27}$ The mixed MA-CTA lamellar phases form after coalescence under this effective attractive force. Conversely, upon melting, the mixed lamellar phases disperse again in the liquid MA phase and lose long-range correlation.

Consistently with the generic phase diagram proposed to describe the segregation of nanoparticles upon freezing of the solvent, ${ }^{28}$ the morphology of the aqueous domains in the solid phase is anisotropic (aspect ratio $>5$ ). This is evidenced by optical and fluorescence confocal microscopy (Fig. 7) of mixtures containing an aqueous solution of Rhodamine 6G $(10 \mu \mathrm{M})$ instead of water to label the aqueous phase in confocal images. Comparison between optical and confocal images (Fig. 7a and b) of the same zone shows the two different types of crystals: myristic acid is assigned to the dark areas in confocal images, whereas the bright dye-rich areas are assigned to the mixed $\mathrm{MA}-\mathrm{CTAB}-$ water crystals. The optical observation confirms the phase segregation between myristic acid and the mixed lamellar phases, as evidenced by the X-ray scattering at small angles (Fig. 4), and 3D reconstruction from the confocal images (Fig. 7c) where an aspect ratio of the mixed MA-CTA-water lamellar crystals is found to be above 5 .

This situation is consistent with the so-called "unstable" regime of segregation ${ }^{28}$ expected for the migration of nanometer-sized domains at freezing front velocities typical for myristic acid $\left(20 \mu \mathrm{m} \mathrm{s}^{-1}\right.$ at supercooling of a few degrees $\left.{ }^{29}\right)$.

\section{Conclusion}

We therefore have identified the MA-CTA mixtures as potential proton conductors. However, the modest proton conductivity of the as-prepared mixtures $\left(10^{-7} \mathrm{~S} \mathrm{~cm}^{-1}\right)$, as compared to the hypothetical upper values $\left(2 \mathrm{~S} \mathrm{~cm}^{-1}\right)$, stresses on the need for proper formulation into a well-organised film e.g. in terms of percolation. This issue is potentially solved by the bicontinuous microemulsions we have identified in the water-CTAB-MA phase diagram, with molten MA playing both the roles of the oil phase and the co-surfactant. The microemulsions identified in this MA-CTAB-water system show two thermal transitions. The unexpected high-temperature transition between two microemulsions has been assigned to the presence of the mixed MACTA film. As it occurs in a highly imbalanced microemulsion, it has no structural signature. Our first conclusion is that it suggests a possible and general way to stimulate microemulsions (e.g. change in surface properties by temperature) without changing their nanostructure.

Furthermore, we have shown that upon cooling, the mixed MA-CTA surfactant film segregates very quickly from liquid MA to form the mixed lamellar phases. This general understanding opens possible routes to avoid destruction of the nanostructure in solidifying microemulsions, without having necessarily to prevent crystallisation of the continuous phase. Such nanostructure control is a prerequisite in order to use the temperature-driven solidification of microemulsions for the design of bulk materials with properties controlled at the molecular scale, e.g. the connectivity, the composition and the packing of the interfacial film, and potentially translate directly the $2 \mathrm{D}$ conductivity of the films into high 3D conductivity in bulk materials.

\section{Acknowledgements}

We acknowledge Marc Detrez for technical support on the PAXE beamline and Patrick Haltebourg for the design of the WAXS setup. This project was funded by the Direction Générale de l'Armement and by the CEA-Direction des Sciences de la Matière-Energie program (project E111-9-MISO). The authors thank Prof. P. Barboux (Ecole Nationale Supérieure de Chimie de Paris) for proton conductivity measurements. C. Dejugnat acknowledges the EU for financial support (FEDER-35477: Nano-objets pour la biotechnologie), and C. Routaboul for her help in IR measurements.

\section{Notes and references}

1 K.-D. Kreuer, S. J. Paddison, E. Spohr and M. Schuster, Chem. Rev., 2004, 104, 4637-4678.

2 M. Schuster, T. Rager, A. Noda, K. D. Kreuer and J. Maier, Fuel Cells, 2005, 5, 355-365.

3 M. Prats, J. F. Tocanne and J. Teissie, Eur. J. Biochem., 1987, 162, 379-385.

4 H. Morgan, D. M. Taylor and O. N. Oliveira Jr, Chem. Phys. Lett., 1988, 150, 311-314.

5 H. Morgan, D. Martin Taylor and O. N. Oliveira Jr, Biochim. Biophys. Acta, Biomembr., 1991, 1062, 149-156.

6 G. Béalle, J. Jestin and D. Carrière, Soft Matter, 2011, 7, 10841089.

7 B. Jönsson, P. Jokela, A. Khan, B. Lindman and A. Sadaghiani, Langmuir, 1991, 7, 889-895.

8 T. Zemb, D. Carriere, K. Glinel, M. Hartman, A. Meister, C. Vautrin, N. Delorme, A. Fery and M. Dubois, Colloids Surf., A, 2007, 303, 37-45.

9 Y. Michina, D. Carrière, C. Mariet, M. Moskura, P. Berthault, L. Belloni and T. Zemb, Langmuir, 2009, 25, 698-706.

10 A. Brûlet, D. Lairez, A. Lapp and J.-P. Cotton, J. Appl. Crystallogr., 2007, 40, 165-177.

11 T. Zemb, O. Taché, F. Né and O. Spalla, Rev. Sci. Instrum., 2003, 74, 2456-2462.

12 E. Barsoukov and J. R. Macdonald, Impedance Spectroscopy: Theory, Experiment, and Applications, John Wiley \& Sons, 2005.

13 V. B. P. Leite, A. Cavalli and O. N. Oliveira, Phys. Rev. E: Stat. Phys., Plasmas, Fluids, Relat. Interdiscip. Top., 1998, 57, 6835-6839. 
14 E. Maurer, L. Belloni, T. Zemb and D. Carrière, Langmuir, 2007, 23, 6554-6560.

15 D. Carriere, L. Belloni, B. Demé, M. Dubois, C. Vautrin, A. Meister and T. Zemb, Soft Matter, 2009, 5, 4983-4990.

16 P. Khuwijitjaru, S. Adachi and R. Matsuno, Biosci., Biotechnol., Biochem., 2002, 66, 1723-1726.

17 M. Kahlweit, R. Strey, P. Firman, D. Haase, J. Jen and R. Schomäcker, Langmuir, 1988, 4, 499-511.

18 M. Teubner and R. Strey, J. Chem. Phys., 1987, 87, 3195-3200.

19 L. Arleth, S. Marcelja and T. Zemb, J. Chem. Phys., 2001, 115, 3923-3936.

20 L. Wolf, H. Hoffmann, T. Teshigawara, T. Okamoto and Y. Talmon, J. Phys. Chem. B, 2012, 116, 2131-2137.

21 M. Duvail, J.-F. Dufrêche, L. Arleth and T. Zemb, Phys. Chem. Chem. Phys., 2013, 15, 7133-7141.

22 R. Strey, Colloid Polym. Sci., 1994, 272, 1005-1019.
23 X. Wen and E. I. Franses, J. Colloid Interface Sci., 2000, 231, 42-51.

24 S. T. Shipman, P. C. Douglass, H. S. Yoo, C. E. Hinkle, E. L. Mierzejewski and B. H. Pate, Phys. Chem. Chem. Phys., 2007, 9, 4572-4586.

25 S. Lifson, A. T. Hagler and P. Dauber, J. Am. Chem. Soc., 1979, 101, 5111-5121.

26 M. A. Hartmann, R. Weinkamer, T. Zemb, F. D. Fischer and P. Fratzl, Phys. Rev. Lett., 2006, 97, 018106.

27 S. Deville, E. Saiz, R. K. Nalla and A. P. Tomsia, Science, 2006, 311, 515-518.

28 S. Deville, E. Maire, G. Bernard-Granger, A. Lasalle, A. Bogner, C. Gauthier, J. Leloup and C. Guizard, Nat. Mater., 2009, 8, 966-972.

29 K. Fukui and K. Maeda, J. Chem. Phys., 2000, 112, 15541559. 